\begin{tabular}{c}
\hline Revista de \\
Contabilidade e \\
Organizações \\
\hline www.rco.usp.br
\end{tabular}

\title{
RELAÇÃO ENTRE O CICLO DE VIDA ORGANIZACIONAL E O PLANEJAMENTO EM EMPRESAS METALÚRGICAS DO MUNICÍPIO DE BRUSQUE-SC
}

\author{
RELATIONSHIP BETWEEN THE ORGANIZATIONAL LIFE CYCLE AND PLANNING IN \\ METALLURGICAL COMPANIES OF CITY OF BRUSQUE-SC
}

\author{
Roberto Carlos Klann ; Patrícia Aparecida Klann ${ }^{b}$; \\ Kátia Regina Postaic; Maria José Ribeirod \\ ${ }^{a}$ Doutor em Ciências Contábeis e Administração - Universidade Regional de Blumenau. \\ Professor Convidado do Programa de Pós-Graduação em Ciências Contábeis \\ Universidade Regional de Blumenau; E-mail: rklann@furb.br

\section{Resumo}

Este trabalho tem por objetivo analisar o relacionamento entre os estágios do ciclo de vida organizacional e o processo de planejamento das empresas. Para determinação do estágio do ciclo de vida foi utilizado o modelo teórico proposto por Miller e Friesen (1994). A pesquisa descritiva, desenvolvida por meio de uma amostra por acessibilidade, com análise quantitativa, foi realizada com 30 empresas do setor metalúrgico do município de Brusque-SC. Na análise dos dados foram utilizadas técnicas de estatística descritiva (média), análise discriminante e de correlação. Os resultados apontam que a maior parte das empresas pesquisadas situa-se nas fases de nascimento e declínio. Os artefatos de planejamento mais utilizados são estratégias, objetivos de longo prazo, cenários internos e planos de investimentos (planejamento estratégico), planos de investimentos no ativo permanente (orçamento) e acompanhamento do fluxo de caixa (controle orçamentário). Conclui-se que existe relação entre os estágios do ciclo de vida e o nível de planejamento utilizado pelas empresas. Porém, os artefatos de planejamento são utilizados de maneira diferente, dependendo do estágio de desenvolvimento da empresa.

Palavras-chave: Ciclo de vida organizacional, Planejamento, Empresas metalúrgicas

\section{Abstract}

This paper aims examine the relationship between the stages of organizational life cycle and the process of companies planning. To determine the stage of life cycle it was used the model proposed by Miller and Friesen (1994). The descriptive survey, developed through an accessibility sample, with quantitative analysis, was conducted with 30 companies from metallurgical sector of city of Brusque/SC. In data analysis were used descriptive statistic techniques (mean), discriminant analysis and correlation. The results indicate that the most researched companies are located in the birth and decay phases. The planning artifacts most used are strategies, longterm goals, internal scenarios and investments plans (strategic planning), investment plans in fixed assets (budget) and monitoring cash flow (budget control). We conclude that there is a relation between the life cycle stages and the level of planning used by companies. However, the planning artifacts are used differently, depending of company development stage.

Keywords: Organizational life cycle, Planning, Metallurgical companies. 


\section{INTRODUÇÃ̃O}

Nos últimos anos do século XX ocorreram mudanças no meio empresarial, com profundas alterações no mercado, o surgimento de novas tecnologias, a elevação dos níveis de exigência dos clientes e o crescimento da competitividade entre as empresas. Essas mudanças exigem das organizações uma concentração de esforços para poder se adequar a essa nova realidade. O processo de planejar, pensar a organização e concentrar esforços na medida em que as mudanças vão ocorrendo tem sido fundamental para traçar metas e implantar os meios de alcançá-las.

Abusca do entendimento de como funcionam as organizações direcionou e ainda direciona o surgimento de muitos trabalhos teórico-empíricos, em que um dos principais objetivos se constitui na compreensão de como as empresas se mantêm ativas e com sucesso. Uma das teorias abordadas consiste no estudo sobre a perspectiva do ciclo de vida das organizações, enfatizada pelos estudiosos e apoiada em duas hipóteses.

A primeira é que existe uma relação íntima entre o ciclo de vida das organizações e a estratégia competitiva, já que a etapa do ciclo de vida das organizações em que a empresa se encontra influencia a preferência por determinada estratégia em detrimento das outras, tanto em nível corporativo como em nível de negócio (PÉREZ; SÁNCHEZ, 2004).

A segunda relaciona o modelo de gestão com o estágio do ciclo de vida das organizações, já que para avançar elas precisam implementar estruturas conscientemente planejadas, que não representem soluções somente para uma crise atual, mas que também se encaixam nas próximas fases de crescimento (GREINER, 1998).

Como a estratégia e o modelo de gestão estão ligados ao processo de planejamento, o problema de pesquisa consiste em investigar a relação existente entre o ciclo de vida organizacional e o processo de planejamento das empresas. A questão de pesquisa consiste na seguinte indagação: qual a relação entre o estágio de ciclo de vida organizacional e o processo de planejamento existente em empresas metalúrgicas do município de Brusque-SC?

Diante disso, o objetivo geral do estudo consiste em analisar a relação entre o ciclo de vida organizacional e o processo de planejamento das empresas. Para atingir o objetivo geral, foram delineados dois objetivos específicos: a) verificar em que estágio do ciclo de vida se encontram as empresas do ramo metalúrgico do município de Brusque-SC; b) identificar o nível de planejamento desenvolvido pelas empresas do ramo metalúrgico desse município.

A justificativa para a escolha do tema decorre de uma mudança que vem ocorrendo na economia do município de Brusque-SC nos últimos anos. Conhecida no estado de Santa Catarina como a cidade dos tecidos, nos últimos 15 anos a força da indústria têxtil vem sendo substituída pela indústria metalúrgica, com reflexos econômicos e sociais para o município, relacionados principalmente à mudança na mão de obra, ao foco de exportação de produtos, entre outros.

A utilização do modelo de ciclo de vida para analisar o estágio das organizações do setor metalúrgico no município pode contribuir para melhoria de processos de gestão e para a implantação de políticas públicas destinadas ao financiamento e treinamento de mão de obra, entre outros fatores. Pode ampliar também a compreensão sobre as práticas de planejamento adotadas, contribuindo para o sucesso e o crescimento das empresas. 


\section{REFERENCIAL TEÓRICO}

Nesse tópico abordam-se os conceitos teóricos relacionados ao ciclo de vida organizacional e ao processo de planejamento das organizações.

\subsection{Ciclo de vida organizacional}

As organizações, independentemente do seu tamanho, passam por estágios de desenvolvimento, os quais são denominados ciclo de vida. A cada estágio do ciclo de vida, a organização passa por novas e diferentes situações (BORINELLI, 1998).

O ciclo de vida é amplamente utilizado na biologia, na psicologia e outras ciências. Alguns autores introduziram esse conceito às organizações, cujos estudos buscam analisar suas mudanças estruturais, ou seja, demonstrar a variação de características organizacionais no decorrer de tempo (ADIZES, 2001).

Borinelli (1998) afirma que, ao analisar o ciclo de vida de uma organização, características comuns e essenciais podem ser destacadas. Cada fase alcançada aumenta a complexidade, requerendo assim, uma nova postura gerencial, com buscas de novas estratégias. A literatura apresenta diversos modelos de ciclo de vida organizacional. Por meio das características apresentadas em cada um deles, pode-se identificar o ciclo de cada um desses modelos.

Dentre os diversos modelos, pode-se destacar os de Grainer (1972), Churchill e Lewis (1983), Quinn e Cameron (1983), Miller e Friesen (1984), Scott e Bruce (1987), Kazanjian e Drazin (1990), Mount, Zinger e Forsyth (1993), Baker e Cullen (1993), Moores e Yuen (2001), Adizes (2001), Lester, Parnell e Carraher (2003), Granlund e Taipaleenmäki (2005) e Auzair e Langfield-Smith (2005).

Junqueira (2010) destaca que os estudos que analisam o ciclo de vida das empresas em um modelo semelhante ao da biologia geralmente são subdivididos em cinco estágios:

a) existência - marca o início do desenvolvimento institucional;

b) sobrevivência - as empresas procuram crescer, desenvolvendo alguma formalização em sua estrutura;

c) sucesso - geralmente chamada de maturidade, é caracterizada pela formalização e pela burocracia;

d) renovação - frequentemente chamada de rejuvenescimento, destaca-se pelo desejo da empresa de voltar a ser enxuta, com fomento da inovação e criatividade;

e) declínio - estágio caracterizado por política e poder, em que as organizações podem desaparecer (JUNQUEIRA, 2010).

Dentre esses diversos modelos, optou-se por utilizar nesta pesquisa o modelo de Miller e Friesen (1984), que se destaca não só pela profundidade conceitual, como também pelos testes empíricos realizados. Seu principal objetivo é prever diferenças entre as características ambientais e organizacionais nos diversos estágios de desenvolvimento organizacional.

Miller e Friesen (1984) apresentam cinco estágios do ciclo de vida organizacional: nascimento, crescimento, maturidade, renovação e declínio. Nas fases consideradas inovativas (nascimento, crescimento e renovação) as competências organizacionais estabelecem-se ou se renovam. Já nos estágios considerados conservadores (maturidade e declínio), a ênfase é sobre 
a eficiência.

No nascimento a organização está voltada para sua viabilidade, tem como características principais a juventude, o fator de serem controladas por seus proprietários e com estruturas simples e informais (MILLER; FRIESEN, 1984).

No estágio do crescimento, a organização é um pouco maior, com estrutura mais formal, heterogênea e menos centralizada. Em alguns casos pode haver novos acionistas e quotistas, tornando o ambiente mais competitivo. As técnicas gerenciais são mais desenvolvidas. A linha de produtos é ampliada e mercados são abordados de forma segmentada. A ousadia das decisões ainda se encontra presente, mas reduzida, uma vez que mais gerentes são envolvidos nas decisões. Isso diminui o apetite de risco e a produtividade. $\mathrm{O}$ crescimento ocorre de maneira rápida (FREZATTI; NECYK; SOUZA, 2007; VASCONCELOS, 2007).

No estágio da maturidade, a organização tem estrutura maior, mais formal e burocrática, alcançando um patamar de heterogeneidade, com centralização moderada. O grau de inovação diminui e o crescimento se dá de forma mais lenta arranjos políticos são perseguidos para manter a estabilidade do ambiente e a meta passa a ser a melhoria da eficiência e a lucratividade das operações. A tomada de decisão é conservadora, menos inclinada a assumir riscos (FREZATTI; NECYK; SOUZA, 2007; VASCONCELOS, 2007).

No estágio do crescimento se espera que a empresa tenha estabelecido suas competências e tenha alcançado sucesso por meio dos produtos e mercado. A ênfase está em alcançar crescimento rápido das vendas e acumular recursos, a fim de obter vantagens do ganho de escala. Há o estabelecimento de uma estrutura funcional, com pouca delegação de autoridade a gerentes e com formalização de procedimentos (MILLER; FRIESEN, 1984). Nesse estágio a organização é um pouco maior, com estrutura mais formal, heterogênea e menos centralizada. Em alguns casos pode haver novos acionistas e quotistas, tornando o ambiente mais competitivo. As técnicas gerenciais são mais desenvolvidas. A linha de produtos é ampliada e mercados são abordados de forma segmentada. A ousadia das decisões ainda se encontra presente, mas reduzida, uma vez que mais gerentes são envolvidos nas decisões. Isso diminui o apetite de risco e a produtividade. O crescimento ocorre de maneira rápida (FREZATTI; NECYK; SOUZA, 2007; VASCONCELOS, 2007).

Quando a empresa atinge o estágio da maturidade, o crescimento acompanha um nível de vendas estável, com queda na inovação e com estrutura organizacional mais burocratizada. As metas passam a ser mais homogêneas e pautadas na eficiência (MILLER; FRIESEN, 1984).

No estágio de rejuvenescimento as empresas adotam uma estrutura divisionalizada, para atuar em mercados mais complexos e heterogêneos. Há também ênfase em controles mais sofisticados e sistemas de planejamento (MILLER; FRIESEN, 1984). Os métodos de controle passam a ser mais sofisticados para acompanhar o desempenho. As inovações são substanciais e há uma alta propensão a riscos, apesar de se ter planejamento (FREZATTI; NECYK; SOUZA, 2007).

A fase do declínio revela uma estagnação no mercado, com redução aos estímulos do ambiente externo, queda na rentabilidade e falta de inovação (MILLER; FRIESEN, 1984). Os membros da organização estão mais preocupados com metas pessoais (MINTZBERG, 1979). A estratégia de negócios não é clara, com foco interno para a entidade, com gestores e proprietários mais preocupados com a preservação de recursos do que com clientes (MOORES; YUEN, 2001).

Miller e Friesen (1984) destacam que não há uma sequência lógica para a ocorrência 
desses estágios, podendo-se progredir ou até mesmo regredir por entre as fases de modo não linear. A tendência mais observada, segundo esses autores, é a de se manter na mesma fase, sendo que o tempo de permanência em cada fase varia de modo significativo.

É importante considerar que os mercados não são estáticos e que sua evolução é constante. Em cada estágio do ciclo de vida, a organização altera suas estratégias e políticas. Dificuldades e circunstâncias inesperadas podem aparecer, porém, se a organização for administrada com base em um planejamento adequado, com um orçamento confiável e um controle orçamentário eficaz, poderá obter o desempenho desejado.

\subsection{Planejamento}

Diante da complexidade do cenário empresarial, das turbulências enfrentadas pelas organizações, há uma busca por ferramentas estratégicas que possibilitem às empresas alcançar seus objetivos. Algumas dessas ferramentas estratégicas pelas quais as organizações têm optado são: o planejamento estratégico, o orçamento e o controle orçamentário.

Ao fazer o planejamento e manipular suas variáveis, a organização deverá permanentemente:

- planejar, ou seja, desenvolver as potencialidades de lucro e melhorar as atividades já existentes, estabelecer seus objetivos e formular estratégias e planos de acordo com a realidade para alcançar seus objetivos;

- organizar, subdividindo as tarefas que serão realizadas para alcançar os objetivos da organização e atribuí-las aos colaboradores de acordo com a autoridade e responsabilidade de cada um;

- dirigir, exercer a liderança, implementar e executar os planos, desenvolver condições que motivem seus colaboradores; e

- controlar, exercer diariamente controle dinâmico, de modo que seja ajustado de acordo com a necessidade, de forma agressiva quando for preciso, aperfeiçoando o processo a cada dia para que esteja cada vez mais de acordo com a realidade da empresa e aceitar as mudanças sempre que as mesmas se fizerem necessário (WELSCH, 1983).

O planejamento, orçamento e controle orçamentário devem sempre estar em sintonia Porter (1989) afirma que, em uma organização sem planejamento, o administrador estaria constantemente apagando incêndios, sem saber a causa dos mesmos. Discute-se nessa seção a importância e influência do planejamento estratégico, do orçamento e do controle orçamentário na vida de uma organização.

\subsubsection{Planejamento estratégico}

As discussões sobre o planejamento estratégico tiveram início em meados dos anos de 1960, impulsionadas pela popularidade do livro Estratégia Corporativa, de Igor Ansoff, publicado em 1965 (MINTZBERG, 1994). Segundo Grant (2003), o interesse pela estratégia como área de estudos gerenciais seguiu a difusão do planejamento estratégico entre as 
grandes companhias durante as décadas de 1950 e 1960. A partir de 1980 pesquisas empíricas sobre sistemas de planejamento estratégico focaram em duas áreas principais: o impacto do planejamento estratégico no desempenho das organizações; e o seu papel na tomada de decisão estratégica.

Para Stoner e Freeman (1995), o planejamento estratégico é baseado em duas bases principais: a primeira consiste na determinação de objetivos e a segunda na escolha dos meios para alcançar os objetivos. Sendo assim, deve-se pensar que a estratégia é algo que se desenvolve com o tempo, levando sempre em consideração que estratégia é um processo de decisões inter-racionais e interdependentes, que buscam objetivos definidos previamente, para assim estabelecer harmonia entre a organização e o meio ambiente.

A literatura existente sobre planejamento é ampla e apresenta divergências entre os diversos modelos de planejamento estratégicos estudados. Os modelos são criados a partir do momento em que surgem novas necessidades, tendo como objetivo principal a criação do modelo ideal para cada organização. O que não se pode deixar de ressaltar é que cada organização deve buscar o modelo que vai ao encontro de sua cultura, de seu conhecimento e também do aprendizado da organização.

Portanto, independentemente do modelo de planejamento estratégico que venha a ser adotado pela organização, ele deverá contemplar essas etapas, a fim de que possa atender às necessidades de planejamento da organização em questão. Além, deve servir de base para a elaboração do orçamento da organização.

\subsubsection{Orçamento}

A necessidade de orçar é antiga. Desde a época das cavernas os homens precisavam prever a quantidade de comida necessária para os invernos. Mas a raiz do orçamento contemporâneo se deu em 1689 com o desenvolvimento da Constituição Inglesa, a qual previa que nenhum imposto poderia ser cobrado ou recursos gastos sem a autorização do parlamento. Depois disso ocorreram algumas alterações no século XIX, no governo de Napoleão, que foram refinadas durante a Segunda República e o Segundo Império na França. No Brasil o orçamento passou a ser estudado a partir de 1940. Mesmo assim, era pouco utilizado. Seu auge ocorreu em 1970, quando as organizações começaram a utilizá-lo com mais frequência (LUNKES, 2003).

Garrison e Noreen (2001) tratam o orçamento como um instrumento que representa os planos da administração para o futuro e de que forma esses planos serão realizados. Anthony e Govindarajan (2002) afirmam que o orçamento não é sinônimo de projeção. O primeiro consiste num plano gerencial, que assume a hipótese de que serão tomadas as providências em relação ao setor orçado. Já a segunda é apenas uma previsão do que pode acontecer.

Em relação à evolução da utilização do orçamento, primeiramente predominou o orçamento empresarial, o qual tinha ênfase na projeção e controle dos resultados. Este plano atendia a atividade do próximo período. Femenick et al. (2006) afirmam que o orçamento empresarial consiste no processo por meio do qual as empresas viabilizam as decisões e estratégias oriundas do planejamento.

O orçamento empresarial pode ser dividido em diversos orçamentos específicos, como: orçamento de vendas, orçamento de produção, orçamento de matéria-prima, orçamento de mão 
de obra direta, orçamento de custos indiretos da produção, orçamento de despesa com vendas, orçamento com despesas administrativas, orçamento de investimento, orçamento de aplicação financeira e financiamento e orçamento de caixa. Com base nos relatórios gerados para cada orçamento em separado, a organização pode fazer o que ela espera de um orçamento, que pode ser: reduzir gastos, aumentar os resultados, identificar a diferença de valores orçados para os executados, permitindo que sejam feitas correções e ajustes (HOJI, 2008).

$\mathrm{Na}$ segunda fase de desenvolvimento do orçamento, ocorreram algumas alterações e a revisão era contínua. O orçamento contínuo se destaca dos demais em três principais características que são: permite orçar curtos períodos e de forma mais rápida, atribuir novas variáveis, resultando em um orçamento mais preciso e detalhado. O sistema para esse tipo de orçamento é fácil para implantar e gerenciar as informações, o que contribui para sua precisão (LUNKES, 2003).

O passo seguinte na evolução do orçamento resultou na criação do orçamento base zero, o qual pressupõe que a organização sempre age como se estivesse iniciando suas operações, ou seja, como se estivesse começando do zero, justificando as necessidades dos gastos orçados, nunca se baseando no ano anterior (OLIVEIRA, 2005).

$\mathrm{Na}$ quarta etapa da evolução orçamentária surge um orçamento mais flexível, com orçamentos diferenciados, o que engloba diversos níveis de atividade, sendo construído por centros de responsabilidades, os quais podem determinar a variabilidade de um centro para outro, permitindo o controle, separando o custo fixo do custo variável e incorporando novos métodos de alocação de recursos (OLIVEIRA, 2005).

Outros tipos de orçamento, como o por atividade e o orçamento perpétuo são encontrados na literatura. No entanto, um orçamento não resolve todos os problemas de uma organização. Por isso, ela deve sempre controlar, ajustar o que for necessário para melhorar seu desempenho e permanecer ativa no seu ramo de negócio, olhando sempre para o futuro e aprendendo com as dificuldades. Para isso, a organização deve ter também um bom controle orçamentário.

\subsection{Controle orçamentário}

Enquanto o orçamento mostra os objetivos a serem alcançados pela organização, o controle orçamentário é o processo que garante que o desempenho esteja em conformidade com o orçado, mostrando as divergências, identificando suas causas e criando ações corretivas. Portanto, o controle orçamentário tem o objetivo de possibilitar à organização a tomada de decisão e a correção de falhas existentes, procurando colocá-la no rumo certo. Cada organização deve passar por um processo de adaptação do controle orçamentário, para que este possa atingir o nível perfeito e corresponder às necessidades dos administradores.

Os estudos sobre sistemas de controle orçamentário tiveram forte influência da administração científica e da abordagem racional, tendo como principal representante Anthony (1965). Inicialmente os controles eram vistos como forma de exercer o poder. A partir da década de 50, cresceu o interesse das organizações pela contabilidade. Em 1953, Argyris publicou um artigo cujo tema principal era o controle orçamentário e o seu impacto. O controle orçamentário era criticado pela excessiva forma de racionalidade (SILVA, 2004).

Covaleski et al. (2003) apresentam três perspectivas utilizadas no processo do controle orçamentário. A primeira é a econômica, a qual considera o valor econômico das práticas 
orçamentárias, tanto para os donos quanto para os colaboradores. A segunda é motivacional, que tenta mostrar quais os benefícios que o controle orçamentário pode trazer à organização. A terceira perspectiva, denominada contingencial, tem como objetivo principal a avaliação do desempenho do controle orçamentário.

Para que a organização tenha um bom controle orçamentário é necessário que ela siga seus princípios fundamentais. Esses princípios são entendidos como uma série de técnicas administrativas que orientam as necessidades básicas. Welsch (1983, p. 50) agrupa essas atividades e técnicas como: envolvimento administrativo, adaptação organizacional, Contabilidade por área de responsabilidade, orientação para objetivos, comunicação integral, expectativa realista, oportunidade, aplicação flexível, reconhecimento do esforço individual e do grupo e acompanhamento.

\section{MÉTODO E PROCEDIMENTOS DA PESQUISA}

Nesta seção apresentam-se o método e os procedimentos da pesquisa. Primeiramente é realizado o delineamento da pesquisa, quanto aos seus objetivos, abordagem do problema e coleta dos dados. Na sequência define-se a população e a amostra. Por fim, demonstra-se o método de coleta e análise dos dados pesquisados.

\subsection{Delineamento da pesquisa}

O presente estudo, quanto ao seu objetivo, pode ser caracterizado como uma pesquisa descritiva. O procedimento utilizado para a coleta dos dados é o de levantamento, com aplicação de um questionário com questões fechadas. Em relação à abordagem, essa pesquisa pode ser classificada como quantitativa, com o emprego de técnicas estatísticas das mais simples, como a média, além de técnicas mais sofisticadas, como a análise discriminante e de correlação.

\subsection{População e amostra}

O setor metalúrgico no Brasil, em janeiro de 2008, registrou dois milhões de trabalhadores, somando 5,4\% dos trinta e sete milhões de empregos formais, apresentando um faturamento US\$ 76 bilhões, $21 \%$ a mais que 2007. A importância deste setor para a economia brasileira pode ser vista com a análise do saldo da balança comercial, que em 2008 foi de $47,01 \%$. O Produto Interno Bruto (PIB) do setor metalúrgico representa 2,6\% do PIB nacional. Em relação ao PIB da indústria nacional, representa $8,5 \%$. O setor é considerado básico pelas várias atividades econômicas essenciais no país. Em Santa Catarina, o setor metalúrgico tem projetos de R\$ 732 milhões para o período 2010/2012.

A população estudada consiste nas empresas do ramo metalúrgico da cidade de Brusque-SC. A lista das empresas foi fornecida pelo Sindicato dos Trabalhadores das Indústrias Metalúrgicas, Mecânica e Material Elétrico de Brusque-SC, da qual foram selecionadas 166 empresas. A amostra de pesquisa se deu por acessibilidade, obtendo-se 30 questionários respondidos, representando $18 \%$ da população. Diante disso, não é possível a generalização dos resultados, que somente podem ser atribuídos à amostra pesquisada. 


\subsection{Coleta e análise dos dados}

O contato com as empresas ocorreu por meio de telefonemas, num primeiro momento. Posteriormente, os dados foram coletados por meio de questionário enviado a essas empresas por e-mail e por telefone. Esse questionário foi direcionado ao gerente de controladoria ou diretor administrativo, dependendo da estrutura organizacional de cada empresa.

Das empresas pesquisadas foram analisadas algumas características como: o ano de abertura, mercado em que atuam, faturamento anual, número de colaboradores, função e grau de escolaridade dos respondentes.

Além da caracterização da amostra, foi utilizado o Modelo de Ciclo de Vida Organizacional proposto por Miller e Friesen (1984) para a classificação das empresas quanto ao ciclo de vida organizacional. Na coleta das informações, baseou-se no questionário utilizado por Frezatti et al. (2010). No Quadro 1 foram descritas as perguntas relacionadas ao ciclo de vida organizacional, as quais determinam as principais características de cada estágio do mesmo.

\begin{tabular}{|c|c|c|}
\hline Num. & Indicadores para mensuração do estagio do ciclo de vida & $\begin{array}{l}\text { Ciclo de vida } \\
\text { Organizacional }\end{array}$ \\
\hline 1 & Como organização, somos menores do que a maioria dos nossos concorrentes & nascimento \\
\hline 2 & $\begin{array}{l}\text { Como empresa, somos maiores do que a maioria dos nossos concorrentes, mas não } \\
\text { tão grandes como deveríamos ser. }\end{array}$ & maturidade \\
\hline 3 & Somos uma organização com diretores e acionistas & rejuvenescimento \\
\hline 4 & O poder decisório da organização esta nas mãos do fundador da empresa & nascimento \\
\hline 5 & O poder decisório da organização é dividido entre muitos donos e investidores & crescimento \\
\hline 6 & O poder decisório da organização esta nas mãos de um grande número de acionistas & maturidade \\
\hline 7 & A estrutura organizacional da organização pode ser considerada simples & nascimento \\
\hline 8 & $\begin{array}{l}\text { A estrutura organizacional da organização esta baseada na visão departamental e } \\
\text { funcional }\end{array}$ & maturidade \\
\hline 9 & A estrutura organizacional da organização é formalizada & rejuvenescimento \\
\hline 10 & $\begin{array}{l}\text { A estrutura organizacional da organização é divisional ou matricial com sofisticado } \\
\text { sistema de controle }\end{array}$ & rejuvenescimento \\
\hline 11 & $\begin{array}{l}\text { A estrutura organizacional da organização é centralizada como poucos sistemas de } \\
\text { controle }\end{array}$ & declínio \\
\hline 12 & $\begin{array}{l}\text { Na organização temos varias especializações (contadores, engenheiros, etc.) e, com } \\
\text { isso nos tornamos diferenciados }\end{array}$ & crescimento \\
\hline 13 & $\begin{array}{l}\text { O processamento de informações na organização pode ser descrito como monitorador } \\
\text { de desempenho e facilitador de comunicação entre os departamentos }\end{array}$ & crescimento \\
\hline 14 & $\begin{array}{l}\text { O processamento de informações na organização pode ser descrito como simples, no } \\
\text { estilo "boca a boca" }\end{array}$ & nascimento \\
\hline 15 & $\begin{array}{l}\text { O processamento de informações é sofisticado e necessário para a produção eficiente } \\
\text { e para atingir os resultados requeridos }\end{array}$ & maturidade \\
\hline 16 & $\begin{array}{l}\text { O processamento de informações é muito complexo e utilizado na coordenação de } \\
\text { diversas atividades para melhorar servir aos mercados }\end{array}$ & rejuvenescimento \\
\hline 17 & O processamento de informações não é muito sofisticado & declínio \\
\hline 18 & O processamento de informações é utilizado de maneira não plena & declínio \\
\hline 19 & $\begin{array}{l}\text { O processo decisório é centralizado na alta administração considerado não muito } \\
\text { complexo }\end{array}$ & declínio \\
\hline 20 & $\begin{array}{l}\text { A maioria das decisões da organização é tomada por grupos de gestores de nível } \\
\text { intermediário que utilizam alguma sistemática que ainda é bem superficial }\end{array}$ & crescimento \\
\hline
\end{tabular}

Quadro 1: Indicadores para mensuração do estágio do ciclo de vida

Fonte: adaptado de Frezatti et al. (2009). 
A variável utilizada para a pesquisa do constructo teórico (ciclo de vida) foi uma escala ordinal de 1 a 5 , em que: 1 = concordo totalmente; 2 = concordo; 3 = indiferente; 4 = discordo; e $5=$ discordo totalmente. A confiabilidade dessas 20 questões foi confirmada com base no teste de Alfa de Cronbach, cujo resultado foi de 0,896.

Foi calculada a pontuação total de cada empresa para cada ciclo de vida organizacional. As empresas foram classificadas no estágio em que obtiveram menor pontuação, levando em consideração que a escala utilizada é decrescente, conforme exemplo apresentado na Tabela 1 referente à empresa e1.

Tabela 1: Classificação da empresa e1 quanto ao ciclo de vida - exemplo

\begin{tabular}{|c|c|c|}
\hline Questão & Estágio do Ciclo de Vida & Pontuação \\
\hline 1 & nascimento & 2 \\
\hline 4 & nascimento & 2 \\
\hline 7 & nascimento & 2 \\
\hline \multirow[t]{2}{*}{14} & nascimento & 2 \\
\hline & soma & 8,00 \\
\hline 5 & crescimento & 2 \\
\hline 12 & crescimento & 3 \\
\hline 13 & crescimento & 2 \\
\hline \multirow[t]{2}{*}{20} & crescimento & 3 \\
\hline & soma & 10,00 \\
\hline 2 & maturidade & 3 \\
\hline 6 & maturidade & 4 \\
\hline 8 & maturidade & 3 \\
\hline \multirow[t]{2}{*}{15} & maturidade & 3 \\
\hline & soma & 13,00 \\
\hline 3 & rejuvenescimento & 3 \\
\hline 9 & rejuvenescimento & 3 \\
\hline 10 & rejuvenescimento & 3 \\
\hline \multirow[t]{2}{*}{16} & rejuvenescimento & 3 \\
\hline & soma & 12,00 \\
\hline 11 & declínio & 3 \\
\hline 17 & declínio & 3 \\
\hline 18 & declínio & 4 \\
\hline \multirow[t]{2}{*}{19} & declínio & 3 \\
\hline & soma & 13,00 \\
\hline
\end{tabular}

Fonte: dados da pesquisa.

No caso apresentado na Tabela 1 (empresa e1), o estágio do ciclo de vida em que a empresa foi classificada é o do nascimento, pois apresenta menor pontuação em relação aos outros estágios. Em alguns casos as empresas foram classificadas em mais de uma fase, ou seja, obtiveram a mesma pontuação em fases distintas. Nesse caso, foi realizada a análise discriminante, com auxílio do software Statistical Package for the Social Sciences (SPSS $®$ ) versão 11.5.0.

$\mathrm{Na}$ análise do nível de planejamento adotado pelas empresas pesquisadas, também foi 
utilizado questionário proposto por Frezatti et al. (2010), conforme apresentado no Quadro 2..

\begin{tabular}{|c|c|}
\hline Artefatos considerados & Itens para mensuração dos artefatos \\
\hline \multirow{9}{*}{$\begin{array}{c}\text { Planejamento } \\
\text { estratégico }\end{array}$} & Visão \\
\hline & Missão \\
\hline & Objetivo de longo prazo \\
\hline & Cenários externos \\
\hline & Cenários internos \\
\hline & Estratégias \\
\hline & Plano de investimento \\
\hline & Planos operacionais de longo prazo \\
\hline & BSC como etapa de controle \\
\hline \multirow{6}{*}{ Orçamento } & Premissas econômico-financeiras \\
\hline & Plano de marketing \\
\hline & PSPE- suprimentos, produção e estocagem (quando aplicável) \\
\hline & Plano de RH \\
\hline & Plano de investimento no ativo permanente \\
\hline & Demonstrações contábeis projetadas \\
\hline \multirow{9}{*}{$\begin{array}{c}\text { Controle } \\
\text { orçamentário }\end{array}$} & Acompanha todas as linhas do balanço \\
\hline & Acompanha todas as linhas da demonstração de resultados \\
\hline & Acompanha todas as linhas do fluxo de caixa \\
\hline & Acompanha todas as linhas de custos e despesas \\
\hline & Acompanha o retorno \\
\hline & Acompanha o fluxo de caixa \\
\hline & Acompanha o EVA \\
\hline & O valor da organização \\
\hline & Acompanha os indicadores chave \\
\hline
\end{tabular}

Quadro 2: Itens para mensuração dos artefatos do planejamento

Fonte: Frezatti et al. (2010).

Para as variáveis do objeto do estudo (planejamento estratégico, orçamento e controle orçamentário) foi utilizada uma escala binária, onde "sim" é representado pela nota 1 e "não" pela nota 0 .

Por fim, para determinar a relação entre os estágios do ciclo de vida em que as empresas pesquisadas foram classificadas, com o nível de planejamento adotado por elas, foi realizada a análise de correlação entre o ciclo de vida organizacional e o nível de planejamento das empresas pesquisadas, utilizando-se novamente o software SPSS versão 11.5.0.

\subsection{Limitações do estudo}

As limitações do estudo estão relacionadas à abordagem metodológica utilizada. Primeiramente, o estudo sobre ciclo de vida organizacional pode ser mais aprofundado com pesquisas qualitativas, com escopo longitudinal, que permitem o acompanhamento das empresas 
por período maior de tempo, proporcionando análise mais eficaz sobre as mudanças de estágio de ciclo de vida. No entanto, pesquisas quantitativas com corte transversal já foram realizadas, podendo-se citar como exemplo, Frezatti et al. (2010).

Na coleta dos dados, a escala Likert de 5 pontos utilizada também constitui uma limitação do estudo, pois pode induzir a erro de tendência central, o que pode ter ocorrido, por exemplo, com os resultados da empresa E28.

Além disso, algumas empresas apresentaram a mesma pontuação em diferentes estágios. Isso pode ocorrer em função dessas empresas apresentarem características de mais de um estágio, o que é previsto na literatura (MILLER; FRIESEN, 1994), ou então, se constituir numa limitação do modelo utilizado.

\section{DESCRIÇÃO E ANÁLISE DOS DADOS}

Neste tópico apresentam-se a descrição e análise dos dados da pesquisa, com a classificação das empresas pesquisadas quanto ao ciclo de vida organizacional, o levantamento do nível de planejamento adotado por essas empresas e a análise da relação entre essas duas variáveis.

\subsection{Classificação quanto ao ciclo de vida organizacional}

Utilizando o modelo apresentado anteriormente no Quadro 1, baseado em Frezatti et al. (2010), apresenta-se a pontuação total de cada empresa para cada fase do ciclo de vida organizacional, de acordo com o Quadro 3. As empresas foram classificadas no estágio em que obtiveram menor pontuação, levando em consideração que a escala utilizada é decrescente.

\begin{tabular}{|c|c|c|c|c|c|c|}
\hline \multirow{2}{*}{ Empresas } & \multicolumn{5}{|c|}{ Pontuação } & \multirow{2}{*}{ Classificação } \\
\hline & nascimento & crescimento & maturidade & rejuvenescimento & declínio & \\
\hline e1 & 8 & 10 & 13 & 12 & 13 & Nascimento \\
\hline $\mathrm{e} 2$ & 4 & 15 & 8 & 9 & 13 & Nascimento \\
\hline e3 & 12 & 16 & 13 & 9 & 12 & Rejuvenescimento \\
\hline e4 & 10 & 9 & 11 & 9 & 11 & $\begin{array}{l}\text { crescimento/ } \\
\text { rejuvenescimento }\end{array}$ \\
\hline e5 & 8 & 10 & 10 & 11 & 14 & Nascimento \\
\hline e6 & 14 & 11 & 13 & 19 & 8 & Declínio \\
\hline e7 & 14 & 11 & 13 & 19 & 8 & Declínio \\
\hline e8 & 10 & 14 & 12 & 12 & 14 & Nascimento \\
\hline e9 & 17 & 10 & 15 & 10 & 13 & $\begin{array}{l}\text { crescimento/ } \\
\text { rejuvenescimento }\end{array}$ \\
\hline $\mathrm{e} 10$ & 11 & 14 & 15 & 14 & 14 & Nascimento \\
\hline e11 & 14 & 12 & 10 & 8 & 15 & Rejuvenescimento \\
\hline $\mathrm{e} 12$ & 13 & 10 & 10 & 12 & 12 & crescimento/maturidade \\
\hline e13 & 13 & 12 & 11 & 9 & 15 & Rejuvenescimento \\
\hline $\mathrm{e} 14$ & 16 & 11 & 10 & 6 & 8 & Rejuvenescimento \\
\hline
\end{tabular}


Continuação do Quadro 3 ...

\begin{tabular}{|c|c|c|c|c|c|c|}
\hline \multirow{2}{*}{ Empresas } & \multicolumn{5}{|c|}{ Pontuação } & \multirow{2}{*}{ Classificação } \\
\cline { 2 - 7 } & nascimento & crescimento & maturidade & rejuvenescimento & declínio & Declínio \\
\hline e15 & 12 & 13 & 17 & 15 & 7 & Declínio \\
\hline e16 & 10 & 17 & 13 & 16 & 9 & maturidade/ \\
\hline e18 & 13 & 13 & 12 & 12 & 7 & Declínio \\
\hline e19 & 8 & 20 & 16 & 20 & 14 & nascimento/crescimento \\
\hline e20 & 12 & 11 & 14 & 12 & 9 & Declínio \\
\hline e21 & 8 & 14 & 14 & 9 & 8 & nascimento/declínio \\
\hline e22 & 9 & 18 & 19 & 17 & 11 & nascimento \\
\hline e23 & 7 & 10 & 11 & 13 & 12 & nascimento \\
\hline e24 & 11 & 17 & 11 & 16 & 13 & nascimento/maturidade \\
\hline e25 & 6 & 9 & 13 & 13 & 12 & nascimento \\
\hline e26 & 9 & 14 & 17 & 16 & 13 & Nascimento \\
\hline e27 & 14 & 11 & 13 & 19 & 8 & Declínio \\
\hline e28 & 12 & 12 & 12 & 12 & 12 & Todas \\
\hline e29 & 8 & 20 & 16 & 18 & 13 & Nascimento \\
\hline e30 & 10 & 14 & 10 & 12 & 14 & nascimento/maturidade \\
\hline
\end{tabular}

Quadro 3: Classificação das empresas quanto ao ciclo de vida

Fonte: dados da pesquisa.

Diante das respostas obtidas por meio dos indicadores de mensuração do estágio do ciclo de vida organizacional, observou-se que todas as empresas apresentam características de todas as fases. No entanto, algumas possuem características mais fortes de uma fase, enquanto outras apresentam características fortes de duas ou mais fases.

Por exemplo, a empresa "el" possui características mais preponderantes de um único estágio de ciclo de vida, no caso, nascimento. Já empresas como a “e 17” apresentam características de dois ou mais estágios. Existem também as empresas que possuem características de todos os estágios do ciclo de vida, como é o caso da empresa "e28".

Para resolver esse problema de classificação, utilizou-se a Análise Discriminante, calculada por meio do software SPSS 11.5, para determinar a precisão da classificação efetuada no Quadro 3, com base na pontuação mais baixa obtida.

Corrar, Dias Filho e Paulo (2009, p. 6) afirmam que a análise discriminante tem o "objetivo de entender as diferenças de grupos com intuito de prever a possibilidade que um indivíduo ou objeto pertença a uma determinada classe ou grupo em particular, com base em diversas variáveis independentes".

No entanto, a análise discriminante possui alguns pressupostos que precisam ser atendidos, antes que se possam analisar seus resultados. Fávero et al. (2009) apontam dois pressupostos principais: a) normalidade multivariada das variáveis explicativas; e b) homogeneidade das matrizes de variância e covariância para os grupos. Além desses dois pressupostos, esses autores ressaltam a inexistência de outliers, a presença de linearidade das relações e a ausência de multicolinearidade das variáveis explicativas como pressupostos da análise discriminante. 
Para testar a normalidade das variáveis foi utilizado o teste One-Sample KolmogorovSmirnov no SPSS, em nível de significância de 5\%. Com base neste teste, $\mathrm{H}_{0}$ pressupõe distribuição normal dos dados da variável enquanto $\mathrm{H}_{1}$ representa uma distribuição não normal. Os resultados do teste One-Sample Kolmogorov-Smirnov para a normalidade dos dados é apresentado na Tabela 2.

Tabela 2: Resultado do teste de normalidade dos dados

\begin{tabular}{|c|c|c|c|c|c|c|}
\hline & & NASC_1 & CRESC_2 & MAT_3 & REJUV_4 & DECL_5 \\
\hline $\mathrm{N}$ & & 30 & 30 & 30 & 30 & 30 \\
\hline Normal Parameters & Mean & 10,867 & 12,867 & 12,833 & 12,967 & 11,467 \\
\hline \multirow{4}{*}{$\begin{array}{l}\text { Most Extreme } \\
\text { Differences }\end{array}$} & $\begin{array}{l}\text { Std. } \\
\text { Deviation }\end{array}$ & 3,014 & 3,203 & 2,520 & 3,774 & 2,529 \\
\hline & Absolute & 0,113 & 0,153 & 0,174 & 0,168 & 0,217 \\
\hline & Positive & 0,096 & 0,153 & 0,174 & 0,168 & 0,148 \\
\hline & Negative & $-0,113$ & $-0,085$ & $-0,097$ & $-0,089$ & $-0,217$ \\
\hline Kolmogorov-Smirnov Z & & 0,620 & 0,840 & 0,951 & 0,919 & 1,188 \\
\hline Asymp. Sig. (2-tailed) & & 0,837 & 0,481 & 0,326 & 0,367 & 0,119 \\
\hline
\end{tabular}

Diante dos resultados apresentados na Tabela 2, constata-se que não existem evidências para se rejeitar $\mathrm{H}_{0}$ para todas as variáveis (Sig. > 0,05). Portanto, o primeiro pressuposto da análise discriminante foi atendido. As matrizes de covariância e de correlação contribuem para a avaliação da relação entre as variáveis, o que segundo Fávero et al. (2009), permitem notar a presença de multicolinearidade entre os elementos.

Tabela 3: Matrizes de covariância e correlação para todos os grupos

\begin{tabular}{l|l|c|c|c|c|c}
\hline & & NASC_1 & CRESC_2 & MAT_3 & REJUV_4 & DECL_5 \\
\hline Covariance & NASC_1 & 4,304 & $-0,637$ & 1,584 & 2,643 & $-0,037$ \\
& CRESC_2 & $-0,637$ & 10,340 & 3,359 & 3,497 & $-0,213$ \\
& MAT_3 & 1,584 & 3,359 & 5,860 & 4,023 & $-1,101$ \\
& REJUV_4 & 2,643 & 3,497 & 4,023 & 9,071 & $-1,276$ \\
& DECL_5 & $-0,037$ & $-0,213$ & $-1,101$ & $-1,276$ & 3,033 \\
\hline \multirow{6}{*}{ Correlation } & NASC_1 & 1,000 & $-0,096$ & 0,315 & 0,423 & $-0,010$ \\
& CRESC_2 & $-0,096$ & 1,000 & 0,431 & 0,361 & $-0,038$ \\
& MAT_3 & 0,315 & 0,431 & 1,000 & 0,552 & $-0,261$ \\
& REJUV_4 & 0,423 & 0,361 & 0,552 & 1,000 & $-0,243$ \\
& DECL_5 & $-0,010$ & $-0,038$ & $-0,261$ & $-0,243$ & 1,000 \\
\hline
\end{tabular}

Fonte: dados da pesquisa.

A matriz de covariância é utilizada para obtenção da matriz de correlação. Na Tabela 3 verifica-se que a matriz de correlação não aponta coeficientes de correlação significativos entre as variáveis, indicando não haver problemas relacionados à multicolinearidade das variáveis explicativas. Outro teste realizado foi o da homogeneidade das matrizes de variância e covariância para os grupos, por meio do teste Box's M no SPSS. Os resultados são apresentados na Tabela 3. 
Tabela 4: Teste Box's M para todos os grupos

\begin{tabular}{l|l|c}
\hline Box's M & & 102,624 \\
\hline F & Approx. & 2,163 \\
& df1 & 30 \\
& df2 & 964,005 \\
& Sig. & 0,000 \\
\hline
\end{tabular}

Fonte: dados da pesquisa.

O resultado da Tabela 4 indica violação da premissa da homogeneidade das matrizes de variância e covariância (Sig. < 0,05). Segundo Corrar, Dias Filho e Paulo (2009), esse problema pode estar relacionado ao tamanho da amostra ou diferença de tamanho dos grupos, que não é significativa nesta análise, ou pela ausência de normalidade nos dados. Quanto à amostra, Fávero et al. (2009) sugerem pelo menos 20 observações para cada variável explicativa, o que foi atendido nesta análise (30 observações). A normalidade dos dados também foi atendida, conforme já apresentado na Tabela 2. Resta a diferença do tamanho dos grupos, que pode estar afetando o teste Box's M. No entanto, como este problema não é significativo para esta análise, decidiu-se prosseguir com o cálculo da análise discriminante, a fim de testar a classificação correta dos grupos quanto ao ciclo de vida organizacional, conforme apresentado no Quadro 4.

\begin{tabular}{|c|c|c|c|c|c|c|c|c|c|c|c|}
\hline \multirow{3}{*}{\multicolumn{2}{|c|}{ Case Number }} & \multirow{4}{*}{$\begin{array}{r}\text { Actual } \\
\text { Group } \\
\\
1\end{array}$} & \multicolumn{5}{|c|}{ Highest Group } & \multicolumn{4}{|c|}{ Discriminant Scores } \\
\hline & & & \multirow{2}{*}{$\begin{array}{l}\text { Predicted } \\
\text { Group }\end{array}$} & \multicolumn{2}{|c|}{$\begin{array}{c}P(D>d \mid \\
G=g)\end{array}$} & \multirow[t]{2}{*}{$\begin{array}{c}\mathrm{P}(\mathrm{G}=\mathrm{g} \\
\mathrm{D}=\mathrm{d})\end{array}$} & \multirow{2}{*}{$\begin{array}{c}\text { Squared } \\
\text { Mahalanobis } \\
\text { Distance to } \\
\text { Centroid }\end{array}$} & \multirow[t]{2}{*}{$\begin{array}{c}\text { Function } \\
1\end{array}$} & \multirow[t]{2}{*}{$\begin{array}{c}\text { Function } \\
2\end{array}$} & \multirow[t]{2}{*}{$\begin{array}{c}\text { Function } \\
3\end{array}$} & \multirow[t]{2}{*}{$\begin{array}{c}\text { Function } \\
4\end{array}$} \\
\hline & & & & $\mathrm{p}$ & dt & & & & & & \\
\hline \multirow[t]{30}{*}{ Original } & 1 & & 1 & 0,855 & 4 & 0,904 & 1,339 & 2,233 & 0,586 & $-0,770$ & $-0,660$ \\
\hline & 2 & 1 & 1 & 0,660 & 4 & 0,951 & 2,412 & 2,069 & 0,416 & 1,434 & 0,642 \\
\hline & 3 & 4 & 4 & 0,682 & 4 & 0,964 & 2,291 & $-1,794$ & 1,336 & $-0,096$ & 1,500 \\
\hline & 4 & 4 & $5 * *$ & 0,296 & 4 & 0,567 & 4,912 & $-0,357$ & 0,482 & $-0,866$ & $-0,713$ \\
\hline & 5 & 1 & 1 & 0,720 & 4 & 0,930 & 2,084 & 1,813 & 0,912 & 0,524 & $-0,964$ \\
\hline & 6 & 5 & 5 & 0,474 & 4 & 0,995 & 3,526 & $-1,050$ & $-2,580$ & 0,437 & $-1,372$ \\
\hline & 7 & 5 & 5 & 0,474 & 4 & 0,995 & 3,526 & $-1,050$ & $-2,580$ & 0,437 & $-1,372$ \\
\hline & 8 & 1 & 1 & 0,512 & 4 & 0,671 & 3,284 & 0,734 & 1,099 & 0,757 & 0,270 \\
\hline & 9 & 4 & 4 & 0,773 & 4 & 0,999 & 1,797 & $-2,666$ & 2,170 & $-1,312$ & $-0,260$ \\
\hline & 10 & 1 & 1 & 0,817 & 4 & 0,936 & 1,557 & 1,178 & 1,031 & $-0,079$ & 0,353 \\
\hline & 11 & 4 & 4 & 0,623 & 4 & 0,982 & 2,622 & $-2,043$ & 2,649 & 0,964 & $-0,089$ \\
\hline & 12 & 3 & 3 & 0,633 & 4 & 0,423 & 2,564 & $-1,239$ & 0,338 & 0,784 & $-1,138$ \\
\hline & 13 & 4 & 4 & 0,589 & 4 & 0,913 & 2,815 & $-1,111$ & 2,415 & 0,642 & $-0,085$ \\
\hline & 14 & 4 & 4 & 0,012 & 4 & 0,998 & 12,926 & $-5,660$ & 0,483 & $-0,687$ & 0,199 \\
\hline & 15 & 5 & 5 & 0,411 & 4 & 0,998 & 3,962 & $-0,870$ & $-1,751$ & $-2,089$ & 0,470 \\
\hline & 16 & 5 & 5 & 0,652 & 4 & 0,944 & 2,461 & $-0,200$ & $-1,794$ & 0,805 & 0,869 \\
\hline & 17 & 5 & $4 * *$ & 0,666 & 4 & 0,509 & 2,379 & $-1,346$ & 0,571 & 0,466 & 0,005 \\
\hline & 18 & 5 & 5 & 0,203 & 4 & 0,998 & 5,950 & $-1,429$ & $-2,957$ & 0,745 & 1,551 \\
\hline & 19 & 2 & 2 & 1,000 & 4 & 0,505 & 0,000 & 2,379 & 1,474 & $-1,370$ & $-0,969$ \\
\hline & 20 & 5 & 5 & 0,679 & 4 & 0,943 & 2,310 & $-1,143$ & $-0,538$ & $-1,395$ & $-0,142$ \\
\hline & 21 & 5 & 5 & 0,214 & 4 & 0,943 & 5,803 & $-0,490$ & $-0,580$ & $-1,939$ & 1,320 \\
\hline & 22 & 1 & 1 & 0,312 & 4 & 0,986 & 4,767 & 2,064 & $-0,664$ & $-1,177$ & 1,768 \\
\hline & 23 & 1 & 1 & 0,768 & 4 & 0,976 & 1,822 & 2,341 & $-0,381$ & 0,053 & $-1,029$ \\
\hline & 24 & 3 & 3 & 0,799 & 4 & 0,907 & 1,654 & 0,212 & $-0,288$ & 2,467 & 0,396 \\
\hline & 25 & 1 & 1 & 0,369 & 4 & 0,899 & 4,285 & 3,354 & $-0,265$ & $-1,095$ & $-1,019$ \\
\hline & 26 & 1 & 1 & 0,879 & 4 & 0,975 & 1,195 & 2,723 & 0,156 & $-0,896$ & 0,404 \\
\hline & 27 & 5 & 5 & 0,474 & 4 & 0,995 & 3,526 & $-1,050$ & $-2,580$ & 0,437 & $-1,372$ \\
\hline & 28 & 5 & 5 & 0,422 & 4 & 0,430 & 3,886 & $-0,669$ & 0,469 & 0,197 & $-0,262$ \\
\hline & 29 & 1 & 1 & 0,365 & 4 & 0,995 & 4,317 & 2,668 & $-0,511$ & 0,985 & 1,706 \\
\hline & 30 & 3 & 3 & 0,945 & 4 & 0,793 & 0,754 & 0,398 & 0,881 & 1,637 & $-0,007$ \\
\hline
\end{tabular}

Quadro 4: Análise discriminante para classificação das empresas quanto ao ciclo de vida

Fonte: dados da pesquisa. 
No Quadro 4 a coluna actual group significa os estágios do ciclo de vida organizacional, sendo 1 (nascimento), 2 (crescimento), 3 (maturidade), 4 (rejuvenescimento) e 5 (declínio), conforme classificação efetuada no Quadro 3, a partir da fase com menor pontuação observada.

Nas empresas classificadas no Quadro 3 em mais de um estágio, optou-se, na análise discriminante, por classificá-las no estágio mais avançado encontrado. Por exemplo, no caso da empresa "e28", que possuía características de todas as fases, para a análise discriminante foi classificada como na fase declínio.

Os resultados na análise discriminante indicam que todas as classificações efetuadas foram satisfatórias, com exceção dos casos e4 e e17, que foram reclassificados pela análise discriminante, conforme pode ser observado no Quadro 4. Anteriormente essas empresas tinham sido classificadas nos estágios de rejuvenescimento e declínio, respectivamente.

Com a análise discriminante houve uma nova reclassificação, para declínio e rejuvenescimento, com uma inversão na classificação dessas duas empresas. Portanto, a partir da classificação final obtida com a análise discriminante, constata-se que há, dentre as 30 empresas investigadas, 12 que estão classificadas na fase de nascimento, 3 na fase da maturidade, 5 na fase do rejuvenescimento e 10 na fase do declínio. Dessa forma, nota-se uma concentração das empresas nos extremos dos estágios de ciclo de vida (nascimento e declínio), o que de certa forma, pode representar uma estabilidade para o setor no município analisado, sendo que as empresas em fase de declínio poderão ser substituídas pelas organizações no estágio do nascimento.

A partir desta análise, passa-se então para a fase seguinte da pesquisa, que consiste na verificação do nível de planejamento das empresas pesquisadas.

\subsection{Nível de planejamento das empresas pesquisadas}

Para as variáveis do objeto do estudo (planejamento estratégico, orçamento e controle orçamentário) foi utilizada uma escala binária, em que "sim" é representado pela nota 1 e "não" pela nota 0 . Na Tabela 5 apresenta-se a pontuação total e a pontuação média das 30 empresas pesquisadas.

Observa-se, na Tabela 5, que o controle orçamentário é o artefato de planejamento mais utilizado pelas empresas pesquisadas. Além disso, destaca-se que o percentual médio de empresas com orçamento $(57,8 \%)$ é inferior ao percentual do controle orçamentário $(75,6 \%)$. Tal fato pode decorrer em razão da falta de conhecimento sobre controle orçamentário, ou por falta de orçamento por parte dos respondentes, ou então, pelo fato de algumas questões relativas ao controle orçamentário estarem relacionadas às demonstrações contábeis.

Outro fator de destaque é a pontuação média do artefato de planejamento estratégico, que atingiu 69,6\% da pontuação máxima, o que denota a importância dada pelas empresas pesquisadas em relação a este artefato. Nesse sentido, os itens mais pontuados foram estratégias, objetivos de longo prazo, cenários internos e planos de investimentos, reforçando o foco interno do planejamento estratégico das organizações investigadas. Por outro lado, a utilização do BSC como etapa de controle, utilizado por apenas 30\% das entidades pesquisadas, além dos cenários externos $(50 \%)$ podem ser considerados como itens que precisam ser melhorados dentro do planejamento estratégico dessas organizações. 
Tabela 5: Pontuação das empresas com relação aos artefatos de planejamento

\begin{tabular}{|c|c|c|c|c|}
\hline \multicolumn{2}{|r|}{ Artefatos } & $\begin{array}{l}\text { Pontuação } \\
\text { total }\end{array}$ & $\begin{array}{l}\text { Pontuação } \\
\text { média }\end{array}$ & $\begin{array}{l}\text { Percentual } \\
\text { médio }\end{array}$ \\
\hline \multirow{10}{*}{$\begin{array}{l}\text { Planejamento } \\
\text { estratégico }\end{array}$} & Visão & 23 & 0,77 & $76,7 \%$ \\
\hline & Missão & 21 & 0,70 & $70,0 \%$ \\
\hline & Objetivo de longo prazo & 25 & 0,83 & $83,3 \%$ \\
\hline & Cenários externos & 15 & 0,50 & $50,0 \%$ \\
\hline & Cenários internos & 25 & 0,83 & $83,3 \%$ \\
\hline & Estratégias & 27 & 0,90 & $90,0 \%$ \\
\hline & Plano de investimento & 25 & 0,83 & $83,3 \%$ \\
\hline & Planos operacionais de longo prazo & 18 & 0,60 & $60,0 \%$ \\
\hline & BSC como etapa de controle & 9 & 0,30 & $30,0 \%$ \\
\hline & Sub-total & 188 & 6,27 & $69,6 \%$ \\
\hline \multirow{7}{*}{ Orçamento } & Premissas econômico-financeiras & 18 & 0,60 & $60,0 \%$ \\
\hline & Plano de marketing & 15 & 0,50 & $50,0 \%$ \\
\hline & $\begin{array}{l}\text { PSPE- suprimentos, produção e estocagem } \\
\text { (quando aplicável) }\end{array}$ & 17 & 0,57 & $56,7 \%$ \\
\hline & Plano de RH & 18 & 0,60 & $60,0 \%$ \\
\hline & Plano de investimento no ativo permanente & 21 & 0,70 & $70,0 \%$ \\
\hline & Demonstrações contábeis projetadas & 15 & 0,50 & $50,0 \%$ \\
\hline & Sub-total & 104 & 3,47 & $\mathbf{5 7 , 8 \%}$ \\
\hline \multirow{10}{*}{$\begin{array}{c}\text { Controle } \\
\text { orçamentário }\end{array}$} & Acompanha todas as linhas do balanço & 22 & 0,73 & $73,3 \%$ \\
\hline & $\begin{array}{l}\text { Acompanha todas as linhas da } \\
\text { demonstração de resultados }\end{array}$ & 24 & 0,80 & $80,0 \%$ \\
\hline & $\begin{array}{l}\text { Acompanha todas as linhas do fluxo de } \\
\text { caixa }\end{array}$ & 26 & 0,87 & $86,7 \%$ \\
\hline & $\begin{array}{l}\text { Acompanha todas as linhas de custos e } \\
\text { despesas }\end{array}$ & 25 & 0,83 & $83,3 \%$ \\
\hline & Acompanha o retorno & 26 & 0,87 & $86,7 \%$ \\
\hline & Acompanha o fluxo de caixa & 27 & 0,90 & $90,0 \%$ \\
\hline & Acompanha o EVA & 12 & 0,40 & $40,0 \%$ \\
\hline & O valor da organização & 20 & 0,67 & $66,7 \%$ \\
\hline & Acompanha os indicadores chave & 22 & 0,73 & $73,3 \%$ \\
\hline & Sub-total & 204 & 6,80 & $75,6 \%$ \\
\hline
\end{tabular}

Fonte: dados da pesquisa.

Em relação ao orçamento, constata-se na Tabela 5 que as empresas dão mais importância aos planos de investimentos no ativo permanente $(70 \%)$, o que pode estar relacionado ao ramo de atividade das organizações investigadas (ramo metalúrgico), que requer investimentos consideráveis em ativos fixos. Já os itens menos considerados relacionados ao orçamento foram plano de marketing e demonstrações contábeis projetadas, o que pode denotar certa deficiência do processo orçamentário de algumas entidades pesquisadas.

Por fim, quanto ao controle orçamentário, notou-se forte influência do acompanhamento do fluxo de caixa nessas organizações $(90 \%)$ e pouca utilização do EVA® $(40 \%)$, o que pode demonstrar uma visão mais focada no curto prazo em relação ao controle orçamentário.

Verificada a pontuação das empresas em relação aos artefatos de planejamento (planejamento estratégico, orçamento e controle orçamentário), pode-se analisar então a relação 
entre esses artefatos e os estágios de ciclo de vida organizacional em que se encontram as empresas pesquisadas.

\subsection{Correlação entre o ciclo de vida organizacional e o nível de planejamento das empresas pesquisadas}

Para fazer a correlação entre o ciclo de vida organizacional e o nível de planejamento das empresas pesquisadas utilizou-se novamente o software Statistical Package for the Social Sciences (SPSS ${ }^{\circledR}$ ) versão 11.5.0, conforme a Tabela 6.

Tabela 6: Correlação entre ciclo de vida organizacional e os artefatos de planejamento

\begin{tabular}{|c|c|c|c|c|c|c|c|c|c|}
\hline & & Planest & Orcam & Controrc & Nasc & Cresc & Mat & Rejuv & Decl \\
\hline \multirow[t]{3}{*}{ Planest } & $\begin{array}{l}\text { Pearson } \\
\text { Correlation }\end{array}$ & 1 &, $706(* *)$ &, $467(* *)$ &,- 176 &,- 268 &,$- 385\left(^{*}\right)$ &,$- 485(* *)$ &, $602(* *)$ \\
\hline & Sig. (2-tailed) & & ,000 & ,009 & ,353 & ,152 & ,036 & ,007 & ,000 \\
\hline & $\mathrm{N}$ & 30 & 30 & 30 & 30 & 30 & 30 & 30 & 30 \\
\hline \multirow[t]{3}{*}{ Orcam } & $\begin{array}{l}\text { Pearson } \\
\text { Correlation }\end{array}$ &, $706(* *)$ & 1 &, $708(* *)$ &,- 350 &,- 341 &,- 279 &,$- 598(* *)$ &, $618(* *)$ \\
\hline & Sig. (2-tailed) & ,000 & & ,000 & 058 & 065 & , 136 & ,000 & ,000 \\
\hline & $\mathrm{N}$ & 30 & 30 & 30 & 30 & 30 & 30 & 30 & 30 \\
\hline \multirow[t]{3}{*}{ Controrc } & $\begin{array}{l}\text { Pearson } \\
\text { Correlation }\end{array}$ &, $467(* *)$ &, $708(* *)$ & 1 &,- 307 &,- 195 &,- 338 &,$- 652(* *)$ &, $499(* *)$ \\
\hline & Sig. (2-tailed) & ,009 &, 000 & & ,099 & 301 & ,068 & ,000 & ,005 \\
\hline & $\mathrm{N}$ & 30 & 30 & 30 & 30 & 30 & 30 & 30 & 30 \\
\hline \multirow[t]{3}{*}{ Nasc } & $\begin{array}{l}\text { Pearson } \\
\text { Correlation }\end{array}$ &,- 176 &,- 350 &,- 307 & 1 &,- 109 &, 051 &, 048 &,- 308 \\
\hline & Sig. (2-tailed) & ,353 & ,058 & ,099 & &, 566 & ,787 & 801 & ,098 \\
\hline & $\mathrm{N}$ & 30 & 30 & 30 & 30 & 30 & 30 & 30 & 30 \\
\hline \multirow[t]{3}{*}{ Cresc } & $\begin{array}{l}\text { Pearson } \\
\text { Correlation }\end{array}$ &,- 268 &,- 341 &,- 195 &,- 109 & 1 &, $394(*)$ &, $422(*)$ &,- 103 \\
\hline & Sig. (2-tailed) & ,152 & ,065 & ,301 & ,566 & & 031 & 020 &, 589 \\
\hline & $\mathrm{N}$ & 30 & 30 & 30 & 30 & 30 & 30 & 30 & 30 \\
\hline \multirow[t]{3}{*}{ Mat } & $\begin{array}{l}\text { Pearson } \\
\text { Correlation }\end{array}$ &,$- 385\left(^{*}\right)$ &,- 279 &,- 338 &, 051 &, $394(*)$ & 1 &, $551(* *)$ &,- 323 \\
\hline & Sig. (2-tailed) & ,036 & , 136 & ,068 & ,787 & ,031 & . & ,002 & 082 \\
\hline & $\mathrm{N}$ & 30 & 30 & 30 & 30 & 30 & 30 & 30 & 30 \\
\hline \multirow[t]{3}{*}{ Rejuv } & $\begin{array}{l}\text { Pearson } \\
\text { Correlation }\end{array}$ &,$- 485\left(^{* *}\right)$ &,$- 598\left({ }^{* *}\right)$ &,$- 652(* *)$ & ,048 &, $422\left(^{*}\right)$ &, $551(* *)$ & 1 &,$- 417\left(^{*}\right)$ \\
\hline & Sig. (2-tailed) & ,007 & ,000 & ,000 & 801 & 020 & ,002 & . & 022 \\
\hline & $\mathrm{N}$ & 30 & 30 & 30 & 30 & 30 & 30 & 30 & 30 \\
\hline \multirow[t]{3}{*}{ Decl } & $\begin{array}{l}\text { Pearson } \\
\text { Correlation }\end{array}$ &, $602(* *)$ &, $618(* *)$ &, $499(* *)$ &,- 308 &,- 103 &,- 323 &,$- 417\left(^{*}\right)$ & 1 \\
\hline & Sig. (2-tailed) & ,000 & ,000 & ,005 & ,098 & ,589 & ,082 &, 022 & . \\
\hline & $\mathrm{N}$ & 30 & 30 & 30 & 30 & 30 & 30 & 30 & 30 \\
\hline
\end{tabular}

Fonte: dados da pesquisa. 
As variáveis utilizadas pelo software (planest, orcan, control orc, nasc, cresc, mat, rejuv e decl) significam, respectivamente, planejamento estratégico, orçamento, controle orçamentário, nascimento, crescimento, maturidade, rejuvenescimento e declínio.

$\mathrm{Na}$ correlação entre os estágios do ciclo de vida organizacional e os artefatos de planejamento utilizou-se o asterisco $\left(^{*}\right)$ para determinar onde existe a correlação com significância em nível de $95 \%$ e dois asteriscos $(* *)$ para determinar correlação significativa em nível de $99 \%$.

A primeira análise que pode ser feita é quanto ao grau de relacionamento entre os artefatos de planejamento pesquisados. Todos apresentam correlação significativa entre si. Isso denota que nas empresas pesquisadas, o planejamento estratégico, o orçamento e o controle orçamentário são utilizados de maneira conjunta na maioria das vezes.

Quanto ao ciclo de vida, constatou-se que as empresas nos estágios do nascimento e crescimento não apresentam correlação significativa com nenhum dos artefatos do planejamento. Isso significa que as empresas dessas fases, embora possam utilizar esses artefatos, não o fazem de modo significativo. Isso vai ao encontro do preconizado no modelo de Miller e Friesen (1984), que relata haver pouco controle formal e sistema de informação precário na fase do nascimento, sendo que os gerentes utilizam o método intuitivo no processo de gestão. Tal fato também foi observado por Junqueira (2010), que não encontrou influência da Ciclo de Vida Operacional (CVO) sobre os artefatos do Sistema de Controle Gerencial (SCG) ao pesquisas 120 empresas brasileiras de grande porte.

No estágio da maturidade, constatou-se correlação significativa apenas para o artefato de planejamento estratégico. Portanto, as empresas pesquisadas que se encontram nesta fase apresentam forte grau de utilização do planejamento estratégico. Embora possam utilizar também o orçamento e o controle orçamentário, esses não se mostraram significativos nesta fase. Miller e Friesen (1984) apontam melhorias no planejamento nesta fase, quando comparada com as fases anteriores, o que justifica o coeficiente de correlação significativo no planejamento estratégico, embora o mesmo não tenha ocorrido com o orçamento e o controle orçamentário.

No estágio de rejuvenescimento todos os artefatos apresentam correlação significativa com esta fase do ciclo de vida, significando que essas empresas apresentam nível de planejamento satisfatório. Segundo Miller e Friesen (1984), nesta fase do ciclo de vida os métodos de controle tornam-se mais sofisticados para acompanhamento do desempenho organizacional, o que vai ao encontro dos resultados desta fase. Os resultados do estudo de Moores e Yuen (2001) indicam que a formalidade dos sistemas de contabilidade gerencial aumenta do nascimento para o crescimento e da maturidade para o rejuvenescimento, o que corrobora os resultados até aqui encontrados.

Na fase de declínio, pôde-se constatar que as empresas pesquisadas apresentam forte grau de correlação com os artefatos de planejamento. No entanto, enquanto nos demais estágios essa correlação era negativa - pois a escala do ciclo de vida era decrescente, enquanto a escala do planejamento era crescente - na fase do declínio, essa correlação apresentou-se positiva.

Isso significa que, quanto melhor caracterizado nesta fase, menor o nível de planejamento apresentado. Miller e Friesen (1984) apontam também para uma redução nos instrumentos de controle internos e externos nesta fase, regredindo para soluções simples diante dos graves problemas enfrentados. Moores e Yuen (2001) também destacam a diminuição na formalidade dos sistemas de contabilidade gerencial da fase do rejuvenescimento para a fase do declínio. Portanto, os resultados da pesquisa para esta fase do ciclo de vida também estão de acordo com o preconizado na literatura. 
De maneira geral, a análise de correlação aponta para uma utilização menor dos artefatos de planejamento nas fases iniciais do ciclo de vida, elevando sua utilização nas fases de maturidade e rejuvenescimento, com a posterior queda na fase de declínio. Esses resultados estão, de certa forma, coerentes com os apontados por Miller e Friesen (1984) e Moores e Yuen (2001).

\section{CONCLUSÕES}

O objetivo desse artigo foi analisar o relacionamento entre os estágios do ciclo de vida organizacional e o processo de planejamento das empresas. Escolheram-se como objeto de análise as empresas do ramo metalúrgico do município de Brusque/SC.

As empresas selecionadas, com base em amostra por acessibilidade, possuíam características bastante diferenciadas, como níveis de faturamento, tempo de atividade e número de colaboradores.

Em relação ao primeiro objetivo específico, que foi verificar em que estágio do ciclo de vida estavam as empresas do ramo metalúrgico de Brusque, constatou-se que a maior parte encontrava-se nos dois extremos dos estágios do ciclo de vida, o estágio do nascimento e do declínio. Outra observação a ser pontuada decorre da dificuldade de enquadramento das empresas nas respectivas fases, pois geralmente apresentam características peculiares a mais de uma fase.

Quanto ao segundo objetivo específico, identificar o nível de planejamento desenvolvido pelas empresas do ramo metalúrgico de Brusque, observou-se que o artefato de controle orçamentário é o mais utilizado pelas empresas pesquisadas, sendo superior ao próprio índice de utilização do orçamento. No entanto, grande parte das questões relacionadas ao controle orçamentário remetia a informações constantes nas demonstrações contábeis das empresas, o que pode ter levado e esse resultado.

Conclui-se, portanto, que embora quase a metade das empresas pesquisadas tenha declarado não utilizar o orçamento, elas buscam informações nas demonstrações contábeis em seu processo de planejamento. Contudo, seu processo de planejamento pode ficar prejudicado, se embasado apenas em informações passadas, deixando de levar em conta projeções futuras (orçamento).

A respeito do objetivo geral, constatou-se que não existe correlação entre o ciclo de vida e o processo de planejamento nas primeiras fases, o que vai ao encontro do preconizado na literatura sobre o ciclo de vida organizacional. As empresas situadas nas fases iniciais do ciclo de vida, não estão preocupadas e nem dispõem de tempo suficiente para o planejamento.

Com o avanço para as fases da maturidade e rejuvenescimento, a correlação com os artefatos de planejamento aumenta, comprovando que empresas que se encontram em fases mais avançadas do ciclo de vida se apresentam mais estruturadas em termos de planejamento.

Na última fase, a do declínio, verificou-se pela análise de correlação que, quanto mais caracterizada a organização está neste estágio, menor é a utilização dos artefatos de planejamento. Esta constatação pode contribuir para o entendimento do próprio processo de deterioração da empresa nesta fase pois, sem planejamento, o horizonte da empresa passa a ser indefinido.

Conclui-se, portanto, que os artefatos de planejamento são utilizados de maneira diferente, dependendo do estágio de desenvolvimento de cada empresa. Corroborando com o 
previsto na literatura, em estágios iniciais do ciclo de vida as empresas não apresentam níveis elevados de planejamento. À medida que avançam nesses estágios, começam a demonstrar utilização mais efetiva de ferramentas ligadas ao planejamento. Portanto, a utilização de artefatos de planejamento pode contribuir para a empresa alcançar estágios mais avançados de seu ciclo de vida.

Como recomendação para futuros estudos, sugere-se a realização de novos trabalhos sobre o tema, com a inclusão de outros ramos de atividade ou outros modelos de ciclo de vida, a fim de confirmar, ou não, os resultados aqui apresentados.

\section{REFERÊNCIAS}

ADIZES, Ichak. Os ciclos de vida das organizações: como e por que as empresas crescem e morrem e o que fazer a respeito. 4. ed. São Paulo: Pioneira, 2001.

ANTHONY, Robert N. Management accounting principles. Homewood: Richard D Irwin, $1965,444 \mathrm{p}$.

ANTHONY, Robert N.; GOVINDARAJAN, Vijay. Sistemas de controle gerencial. São Paulo: Atlas, 2002.

AUZAIR, S. M.; LANGFIELD-SMITH, K. The effect of service process type, business strategy and life cycle stage on bureaucratic MCS in service organizations. Management Accounting Research, [S.1.], v.16, p.399-421, 2005.

BAKER, D. D.; CULLEN, J.B. Administrative reorganization and configurational context: the contingent effects of age, size and change in size. Academy of Management Journal, [S.1.], v.36, n.6, p.1251-1277, 1993.

BORINELLI, Marcio Luiz. A identificação do ciclo de vida das pequenas empresas através das demonstrações contábeis. Disponível em: < http://www.eps.ufsc.br/disserta98/borinelli/ index.html $>$. Acesso em 15 de janeiro de 2010.

CHURCHILL, N. C.; LEWIS, V. L. The five stages of small business growth. Harvard Business Review, n. 61, 1983, p. 30-50.

CORRAR, Luiz J; PAULO, Edilson; DIAS FILHO, José Maria. Análise multivariada. São Paulo: Atlas, 2009.

COVALESKI, Mark et al. Budgeting research: three theoretical perspectives and criteria for selective integration. Journal of Management Accounting Research, v. 15, n. 1, p. 3-49, 2003.

FÁVERO, Luiz Paulo et al. Análise de dados: modelagem multivariada para tomada de decisões. Rio de Janeiro: Elsevier, 2009.

FEMENICK, Tomislav R. et al. Conceitos gerais sobre orçamento. In: FEMENICK, Tomislav R. (Org.). Fundamentos, metodologias e práticas do orçamento empresarial. São Paulo: IPEP, 2006.

FREZATTI, Fábio et al. Perfil de planejamento e ciclo de vida organizacional nas empresas brasileira. Revista de Administração da USP - RAUSP, v. 45, n. 4, p. 383-399, out./Nov./dez. 
2010.

FREZATTI, Fabio; NECYK, George Anthony; SOUZA, Bruno Carlos. Ciclo de vida das organizações e a contabilidade gerencial. In: CONGRESSO DA ASSOCIAÇÃO NACIONAL DOS PROGRAMAS DE PÓS-GRADUAÇÃO EM CIÊNCIAS CONTÁBEIS - ANPCONT. 1. 2007, Gramado. Disponível em: < http://www.anpcont.com.br/site/docs/congressoI/01/ CCG089.pdf $>$. Acesso em: 13 jan. 2010.

GARRISON, Ray H.; NOREEN, Eric W. Contabilidade gerencial. Rio de Janeiro: LTC, 2001.

GRANLUND, M.; TAIPALEENMAKI, J. Management control and controllership in new economy firms- a life cycle perspective. Management Accounting Research, [S.1.], p.73-87, 2005.

GRANT, Robert M. Strategic planning in a turbulent environment: evidence from the oil majors. Strategic Management Journal, v. 24, p. 491-517, 2003.

GREINER, Larry E. Evolution and revolution as organizations grow. Harvard Business Review, v. 76, n. 3, 1998.

HOJI, Masakazu. Administração financeira e orçamentária. 7. ed. São Paulo: Atlas, 2008.

JUNQUEIRA, Emanuel R. Perfil do sistema de controle gerencial sob a perspectiva da teoria da contingência. 2010. 147 f. Tese (Doutorado em Ciências Contábeis) - Universidade de São Paulo, São Paulo, 2010.

KAZANJIAN, R.K.; DRAZIN, R., A stage-contingent model of design and growth for technology-based new ventures. J.Bus. Venturing, [S.1.], n.5, p.137-150, 1990.

LESTER, D., PARNELL, J.A.; CAHARRER, S. Organizational life cycle: a five stage empirical scale. The International Journal of Organizational Analysis, [S.1.], v. 11, n. 4, p. 339-354, 2003.

LUNKES, Rogério João. Contribuição à melhoria do processo orçamentário empresarial. 2003. 174 f. Tese (Doutorado em Engenharia da Produção) - Universidade Federal de Santa Catariana, Florianópolis, 2003.

MILLER, Danny; FRIESEN, Peter. Alongitudinal study of the corporate life cycle. Management Science, v. 30, n. 10, out/1984.

MINTZBERG, Henry. The structuring of organizations: a synthesis of the research. Englewood Cliffs, NJ: Prentice-Hall, 1979.

MINTZBERG, Henry. Rethinking strategic planning part I: pitfalls and fallacies. Long Range Planning, v. 27, n. 3, p. 12-21, 1994.

MOORES, K.; YUEN, S. Management accounting systems and organizational config uration: a life-cycle perspective. Accounting, Organization and Society, [S.1.], v.26, p.351-389, 2001.

MOUNT, J; ZINGER, J.T; FORSYTH, G. R. Organizing for development in the small business. Long Range Planning, Boston, v. 05, n. 26, 1993, p.111-120.

OLIVEIRA, Francisco de. Redução dos custos de manufatura da Gm powertraisn, através da padronização, comparação dos resultados entre diversas plantas e utilização das melhores práticas. 2005. 74 f. Dissertação (Mestrado em Engenharia Automotiva) - Universidade de São 
Paulo, São Caetano do Sul, 2005.

PÉREZ, Matilde García; SÁNCHEZ, Ramón Sabater. Relaciones entre estratégia y ciclo de vida de La empresa. Revista Estratégias, Conocimientos e Innovación II. n. 20, dez.2003 jan. 2004. Disponível em: < http://www.madrimasd.org/revista/revista20/sumario.asp $>$. Acesso em: 21 out. 2010.

PORTER, Michael. Estratégia competitiva: técnicas para análise de indústrias e concorrência. Rio de Janeiro: Campus, 1989.

QUINN, Robert; CAMERON, Kim. Organizational life cycles and shifting criteria of effectiveness some preliminary evidence. Management Science, v. 4, n.4, p. 92-108. feb, 1993.

SCOTT, M.; BRUCE, M.. Five stages of growth in small business. Long Range Planning, London, Bimestral. v. 20, n. 03, 1987, p.45-52.

SILVA, Adriana Cristina da. Caracterização do uso de sistemas de controle orçamentário: um estudo multi - caso. 2004. 139 f. Dissertação (Mestrado em Ciências Contábeis) - Universidade de São Paulo, São Paulo, 2004.

STONER, J.; FREEMAN, E. Administração. Rio de Janeiro: Prentice-Hall, 1995.

VASCONCELOS, Yumara Lucia. Mapas explicativos da insolvência em nível falimentar: as perspectivas de gestores, consultores e acadêmicos. 2007. 263 f. Tese (Doutorado em Administração) - Universidade Federal da Bahia, Salvador, 2007.

WELSCH, Glenn Alber. Orçamento empresarial. 4. ed. São Paulo: Atlas, 1983. 


\section{DADOS DOS AUTORES:}

\section{ROBERTO CARLOS KLANN}

Fundação Universidade Regional de Blumenau, Programa de Pós-Graduação em Ciências Contábeis.

Rua Antonio da Veiga, sala D 202 - Victor Konder

89012-900 - Blumenau, SC - Brasil

\section{PATRÍCIA KLANN}

Centro Universitário de Brusque - Unifebe

Rua Dorval Luz, 123 - Bairro Santa Terezinha -

88352-400 - Brusque, SC - Brasil

\section{KÁTIA REGINA POSTAI}

Centro Universitário de Brusque - Unifebe

Rua Dorval Luz, 123 - Bairro Santa Terezinha

88352-400 - Brusque, SC - Brasil

\section{MARIA JOSÉ RIBEIRO}

Fundação Universidade Regional de Blumenau, Programa de Pós-Graduação em Ciências Contábeis.

Rua Antonio da Veiga, sala D 202 - Victor Konder

89012-900 - Blumenau, SC - Brasil 